DOI 10.37882/2223-2974.2021.03.29

\title{
ИНФОРМАЦИОННЫЕ ТЕХНОЛОГИИ КАК ИНСТРУМЕНТ ПРОФИЛАКТИКИ КОРРУПЦИИ В ОРГАНИЗАЦИЯХ В РОССИИ
}

\section{INFORMATION TECHNOLOGIES AS A TOOL FOR PREVENTING CORRUPTION IN ORGANIZATIONS IN RUSSIA}

\section{R. Khasnutdinov}

Summary: The article deals with certain aspects of prevention of corruption offenses committed in enterprises, organizations and corporations. Prevention of corruption is a priority in anti-corruption activities in enterprises, where measures are taken to prevent corruption, including identifying and subsequently eliminating the causes of corporate corruption. An important role in prevention is assigned to enterprises and organizations themselves, which, in accordance with the law, are obliged to create conditions and take measures to prevent corruption. The effectiveness of the implementation of anti-corruption measures in the organization is significantly increased when using information technologies. The study analyzes the possibilities of information technologies on the example of carrying out certain anticorruption measures recommended to organizations, shows their impact on reducing corruption risks, increasing the transparency of business processes, automating anti-corruption audit, and discusses debatable issues regarding their implementation.

Keywords: corruption; prevention; organization; information technology, digitalization.

\author{
Хаснутдинов Ренат Рафаильевич \\ К.ю.н., доцент, Самарский государственный \\ экономический университет \\ Khasnutdinoff@mail.ru
}

Аннотация: В статье рассматриваются отдельные аспекты профилактики коррупционных правонарушений, совершаемых на предприятиях, в организациях и корпорациях. В деятельности по противодействию коррупции на предприятиях приоритетом является её профилактика, в рамках которых осуществляются мероприятия по предупреждению коррупции, в том числе по выявлению и последующему устранению причин корпоративной коррупции. Важная роль в предупреждении отведена самим предприятиям и организациям, которые в соответствии с законодательством обязаны создавать условия и принимать меры по недопущению коррупционных проявлений. Эффективность работы по внедрению в организации антикоррупционных мер значительно повышается при использовании информационных технологий. В исследовании проанализированы возможности информационных технологий на примере проведения отдельных рекомендуемых организациям антикоррупционных мероприятий, показано их влияние на снижение коррупционных рисков, повышение прозрачности бизнес-процессов, автоматизацию антикоррупционного аудита, рассмотрены дискуссионные вопросы относительно их внедрения.

Ключевые слова: коррупция, предупреждение, организация, информационные технологии, цифровизация.
$\mathrm{K}$ оррупция - это сложное социально-культурное явление, которое эволюционировало параллельно развитию общества. Она несет за собой серьезную опасность для общества и государства во всех сферах жизни. Будучи многоликой, коррупция создает препятствия не только для государственной и муниципальной службы, но и для предпринимательской деятельности, препятствует решению политических и экономических задач, развитию торгово-экономических отношений с другими странами. Согласно докладу генерального прокурора Ю. Чайки на заседании Совета Федерации РФ в 2018 году ущерб от коррупционных преступлений составил 65,7 миллиарда рублей, что на 66 процентов больше, чем в 2017 году (39,6 миллиарда) [1].

Для развития общества основополагающее значение имеет состояние экономики как страны в целом, так и регионов. Объективным результатом процесса трансформации экономики России должно являться занятие конкурентных позиций на мировом рынке, а, следовательно, роль сферы предпринимательства должна возрастать. Развитию конкурентоспособности препятствует коррупция на предприятиях и в организациях, так называемая корпоративная коррупция. Корпоративная коррупция в отличие от других ее видов наносит особенно большой ущерб не только самим организациям, но и экономике страны в целом. Деятельность по противодействию коррупции на предприятиях должна рассматриваться в качестве одного из основных и приоритетных направлений антикоррупционной политики российского государства.

Коррупция на предприятиях и в организациях имеет огромное количество проявлений. Это и ситуации, когда управленческое решение принимается не в целях выгоды предприятия, организации, компании, а в целях личного обогащения лиц, участвующих в принятии данного решения, и ситуации, связанные с незаконным вознаграждением от имени и в интересах организации, и коммерческие подкупы, и корпоративные мошенничества и многое другое. Следствием таких различных проявлений коррупции являются негативные последствия в виде роста расходов предприятия, увеличения стоимости приобретаемых товаров и услуг конечным потреби- 
телем, теневым денежным потокам, ущерба репутации предприятия.

Какими бы эффективными не были средства борьбы с коррупцией у правоохранительных органов государства, выявить и привлечь к уголовной и административной ответственности большинство коррупционеров практически невозможно. Латентность этого вида преступности крайне высока. Поэтому в деятельности по противодействию коррупции на предприятиях приоритетом должна являться её профилактика, то есть предупреждение коррупции, включая выявление и последующее устранение причин коррупции. И здесь важную роль должны играть сами предприятия и организации по ряду причин.

Во-первых, в ст. 13.3 Закона о противодействии коррупции [2] закреплена обязанность организаций и предприятий разрабатывать и принимать меры по предупреждению коррупции. Надзор за исполнением данного законодательного предписания активно осуществляют органы прокуратуры.

Во-вторых, для юридических лиц за совершение коррупционных правонарушений установлены очень высокие штрафы. Так, например, верхний порог санкции ст. 19.28 КоАП РФ за незаконное вознаграждение от имени юридического лица составляет до 100 крат суммы незаконного вознаграждения, но не менее 100 млн. рублей с обязательной конфискацией предмета правонарушения (денег, ценных бумаг). Безусловно, такие высокие штрафы очень сильно бьют по финансовому состоянию предприятий и даже могут привести к банкротству небольших компаний. Поэтому это крайне не выгодно для предприятий. Кроме того, дополнительным негативным последствием для юридических лиц, привлеченных по ст. 19.28 КоАП РФ, является двухлетний запрет на участие в закупках для государственных и муниципальных нужд, установленный требованиями п. 7.1 ч. 1 ст. 31 Федерального закона от 5 апреля 2013 г. № 44-Ф3 «О контрактной системе в сфере закупок товаров, работ, услуг для обеспечения государственных и муниципальных нужд» [3]. В целях реализации этой нормы закона для заинтересованных лиц на сайте Генеральной прокуратуры РФ размещен Реестр юридических лиц, привлеченных к административной ответственности за коррупцию.

Ну и в-третьих, самим организациям выгодно принимать антикоррупционные меры и осуществлять антикоррупционные мероприятия, поскольку коррупция несет для них указанные выше негативные последствия, пагубно влияющие на их устойчивое развитие.

Министерство труда и социальной защиты РФ опубликовало методические рекомендации «Меры по предупреждению коррупции в организациях», в которых предложены ключевые инструменты, которые следует внедрять организациям в целях эффективного предупреждения коррупции. Многие предприятия, выполняя предусмотренную законом обязанность, активно разрабатывают и принимают рекомендованные им меры по предупреждению коррупции.

Огромную роль при внедрении в организации антикоррупционных мер играют информационные технологии. В настоящее время всё большее количество организаций для решения экономических и других задач внедряют в свою деятельность информационные технологии, посредством которых оптимизируются бизнес-процессы, повышается конкурентоспособность, автоматизируются многие внутренние процессы, обеспечивается конкурентное преимущество и другое. О роли и возможностях информационных технологий в устойчивом развитии предприятий и организаций сказано в исследовании С.Л. Поповой [4], об информационных технологиях как технических методах борьбы со злоупотреблениями и коррупцией в сфере закупок подробно изложил Б.М. Бижоев [5]. Отмечаем, что информационные технологии следует рассматривать в качестве серьезного инструмента профилактики коррупции на предприятиях. Продемонстрируем их влияние на повышение эффективности некоторых антикоррупционных мер, рекомендованных для внедрения на предприятиях.

Основополагающей антикоррупционной мерой является разработка и принятие антикоррупционной политики организации, которая определяется особенностью ее деятельности. Помимо принятия указанной политики, ключевое значение имеет информированность работников об установленных подходах в борьбе с коррупцией в организации, о нормативно-правовых актах, об антикоррупционных стандартах. Такую информацию целесообразно размещать на сайте организации в Интернете в специально предусмотренном разделе, который должен быть наглядным и удобным в использовании Доступ к нему должен быть максимально простым с главной страницы сайта (в 1-2 клика). Разумно было бы предусмотреть подразделы, в которых отдельно следует разместить нормативно-правовое регулирование, основные антикоррупционные меры в организации, разъяснения отдельных антикоррупционных положений, примеры коррупционные проявлений и судебную (правоприменительную) практику по ним и т.д. О периодическом обновлении информации об изменениях в антикоррупционных нормативно-правовых актах, об антикоррупционных правилах, стандартах посредством информационных технологий можно сообщать сотрудникам предприятия, например, путем автоматической рассылки на электронную почту или на рабочие компьютеры.

Помимо информирования в организации необходимо предусмотреть периодическое консультирование и 
обучение по вопросам, связанным с противодействием коррупции. И если организация осуществляет эти мероприятия самостоятельно, то применение информационных технологий дистанционного обучения значительно облегчит и ускорит эти процессы. Электронные курсы легко изучаются в любое время с рабочего или домашнего компьютера, в том числе с выполнением предусмотренных программой обучения заданий и прохождением контрольных тестирований. Применение информационных технологий при обучении максимально экономит человеческие и другие ресурсы, а также позволяет организовывать периодическую проверку знаний сотрудников об основных положениях антикоррупционного законодательства, максимально объективно оценивать знания работников предприятий, анализировать и видеть картину об уровне образования сотрудников по вопросам антикоррупционного законодательства по предприятию в целом.

Поэтапному развитию антикоррупционной работы на предприятии должна предшествовать оценка коррупционных рисков, для того чтобы в конечном итоге разработать план мероприятий по их минимизации. Среди основных принципов, которыми необходимо руководствоваться при проведении оценки коррупционных рисков, выделим следующие: анализ бизнеспроцессов, а не личностных качеств, проверка наличия коррупционных рисков всех бизнес-процессов, рационального распределения ресурсов, максимальная конкретизация описания коррупционных рисков, регулярность в проведении оценки коррупционных рисков. Решение задач по минимизации коррупционных рисков значительно облегчается применением информационных технологий. Использование таких систем как CRM (Customer Relationship Management - система управления взаимоотношениями с клиентами), SCM (Supply Chain Management -система управления цепочками поставок), ERP (Enterprise Resource Planning - система управления ресурсами предприятия) позволяют: сделать максимально прозрачными взаимоотношения различных отделов с клиентами (CRM); максимально автоматизировать процессы, связанные с планированием, исполнением и контролем всех затрат сырья, материалов, ресурсов от момента получения заказа до моменты выхода готовой продукции (SCM); максимально автоматизировать процессы, связанные с планированием, учетом, контролем, анализом бизнес-процессов, решением бизнес-задач в масштабе всей организации (ERP). Посредством внедрения указанных информационных технологий предприятие эффективно функционирует на основе процессного подхода [4, с. 75-76], когда управление в организации происходит через процессы, а не функции отдельных работников или подразделений. В результате этого значительно снижаются коррупционные риски: максимально убирается человеческий фактор при принятии каких-либо решений в процессах, которые становятся автоматическими, устраняются различные барьеры и уровни иерархии, решается проблема неэффективного взаимодействия отделов и служб, обеспечивается прозрачность процессов, снижается потребность в промежуточных структурах предприятия. OAO «Газпром» для анализа закупок, управления затратами, сведения к минимуму рисков ошибок прогнозирования, обеспечения прозрачности процессов внедрила систему искусственного интеллекта «Антирутина корпорация», а во многих торговых компаниях активно внедрена и успешно эксплуатируется интеллектуальная система Forecast NOW[6].

Говоря о мерах по снижению коррупционных рисков в организации, нельзя не сказать о таком программном инструменте как умные контракты (смарт контракты), которые активно набирают популярность и уже успели себя положительно зарекомендовать. Смарт-контракт является компьютерной программой, отслеживающей и обеспечивающей исполнение обязательств сторон по договору. Предварительно стороны прописывают в смартконтракте все условия сделки, санкции за их нарушение и невыполнение, скрепляют электронными подписями. После этого процесс исполнения договора автоматизируется и становится подконтрольным самоисполняемому компьютерному коду, записанному в блокчейн. Умный контракт самостоятельно может определить, всё ли исполнено, после чего принять решение о завершении сделки, о выдачи денег, товара, о наложении прописанных штрафов и пеней, о блокировке доступа к активам и т.д. Умные контракты разумно применять для различных сделок, таких как лицензионные платежи, поставка, аренда, закупка оборудования и др. Смарт-контракты легко отслеживать, для них характерны автоматизация, максимальная прозрачность, точность выполнения. Четкие математические алгоритмы компьютерного кода исключают различных посредников, создания каких либо дополнительных барьеров, возможность подкуп, иной человеческий фактор, что обеспечивает высокую минимизацию коррупционных рисков.

В указанных выше методических рекомендациях также говорится об антикоррупционном аудите отдельных операций и сделок как одной из мер, необходимой для внедрения в организациях. Организациям при наличии у них возможностей и ресурсов следует обеспечить дополнительный анализ сделок и операций с высокими коррупционными рисками. Среди таковых могут быть различные крупные закупки, продажа или аренда имущества, сделки связанные с инвестициями или кредитами. Для этого необходимо разработать так называемые «индикаторы коррупции», то есть перечень количественных и качественных показателей, указывающих на возможные коррупционные правонарушения при заключении сделок, совершении операций, принятии решений, а также алгоритмы их выявления. Антикор- 
рупционный аудит целесообразно автоматизировать посредством различных информационных технологий. Например, посредством технологии интеллектуального анализа данных (Data Mining), содержащей различные математические и статистические алгоритмы, можно не только отображать и прогнозировать критичные для бизнеса процессы, а также идентифицировать сделки, операции, бизнес-процессы, подверженные рискам коррупционных проявлений, конфликта интересов, мошенничества, иных правонарушений. Как антикоррупционный программный инструмент технологию (Data Mining) следует разрабатывать для выявления коррупционных проявлений, корпоративных мошенничеств с целью оперативного реагирования на них [7, С. 39]. Следует также сказать о таких аналитических инструментах как SelfMonitoring, Analysis and Reporting Technology (SMART), которые в соответствии с прописанными алгоритмами анализа и оценки рисков проверяют транзакции и бизнес-процессы как в режиме онлайн, так и офлайн, выявляют и обнаруживают различные нарушения, при совершении закупок останавливают платежи по неправильно сформированным или сомнительным операциям, Такие возможности информационных технологий по проверке внутренних процессов предотвращают преступную коррупционную и мошенническую практику, выявляют и предупреждают незаконные финансовые потоки [7, С. 39]. Например, начиная с 2017 года Счетной Палатой РФ для проведения удаленного аудита применяются информационные технологии, которые позволяют выявить более 70 видов нарушений в автоматическом режиме без привлечения инспектора[8].

Коррупционные риски могут возникать не только внутри организации, но и при работе с внешними партнерами, клиентами, поставщиками, которые могут быть замешаны в коррупционных ситуациях. В связи с этим в целях исключения недобросовестных деловых партнеров, предприятиям рекомендуется проводить процедуру по оценке добросовестности партнеров. Такая процедура, получившая название Дью дилидженс (Due Diligence), позволяет собрать максимально объективную информацию о контрагенте на предмет честного ведения им бизнеса и нетерпимости к различного рода коррупционным правонарушениям. Такие сведения могут собираться как в открытых источниках (СМИ, Интернет), так в различных базах данных бесплатного и платного характера. И, конечно же, в такой работе следует прибегать к помощи информационных технологий, посредством которых не только облегчается по времени и объему поиск информации, но и может создаваться своя внутренняя база партнеров организации. Эта база периодически в автоматическом режиме может проверяться на предмет возможных коррупционных рисков работы с контрагентами.

В реализации антикоррупционных мероприятий в ор- ганизациях вполне логично использование множества других информационных технологий, которые помимо решения иных задач, также окажут значительную помощь в профилактике коррупционных проявлений. Например, информационные технологии SIEM-класса, в рамках выполнения задач по информационной безопасности, позволят защитить информацию ограниченного доступа. А применение DLP-систем (Data Leak Prevention) помимо предупреждения утечек конфиденциальных данных позволяет контролировать использование рабочего времени и ресурсов сотрудниками предприятия, мониторить общение между ними в целях раскрытия мошеннических и коррупционных схем на этапе планирования, контролировать правомерность действий работников.

Систематическое внедрение в организации антикоррупционных мер, а также использование в этой работе информационных технологий, связано с определенными расходами. Отчасти и поэтому в настоящее время существуют еще достаточно большое количество организаций, в которых антикоррупционная работа не ведется либо проводится формально. О выявлении большого количества нарушений требований закона о внутрикорпоративной профилактике коррупции органами прокуратуры писал С.К. Илий [9].

Считаем, что поскольку государство напрямую заинтересовано в снижении уровня коррупции, в том числе посредством исполнения организациями своей обязанности по внедрению антикоррупционных мероприятий, то оно для реального действия и выполнения статьи 13.3. Закона о противодействии коррупции должно предусмотреть отдельные статьи финансирования, в том числе направленные на разработку и дальнейшее предоставление информационных технологий, позволяющих снижать коррупционные риски и эффективно предупреждать различного рода коррупционные проявления в организациях. Справедливо отмечают Кузнецов А.А. и Кузнецов П.А. о том, что внедрение информационных технологий быстро не решит проблему коррупции. Данный процесс зависит от финансовых и технических инвестиций на всех уровнях его реализации, и для успеха необходимо, чтобы государственный сектор в этом направлении активно сотрудничал с частным сектором [7, С. 39].

В заключении следует отметить, что работа по профилактике коррупционных правонарушений в организациях является приоритетной в системе противодействия корпоративной коррупции. Ответственную роль в этой работе государство возложило на сами организации и предприятия, которые согласно закону обязаны создавать условия и принимать меры по недопущению коррупционных проявлений. Эффективность работы по внедрению в организации антикоррупционных мер значительно повышается при использовании информационных технологий. Они имеют важное значение, по- 
скольку выполняют не только экономические задачи по оптимизации и автоматизации внутренних процессов, но и, благодаря им, снижаются коррупционные риски, повышается прозрачность бизнес-процессов, возрастает качество антикоррупционного аудита, убираются различные барьеры, посреднические структуры и человеческие факторы, которые потенциально могут привести к коррупционным ситуациям.

В настоящее время внедрение информационных технологий при осуществлении антикоррупционных мероприятий российскими организациями находится в самом начале пути. Это достаточно трудоемкий процесс, который требует и значительных финансовых вложений. Однако, не смотря на это, данная работа осуществляться должна, при чем, не только силами и сред- ствами частных организаций, но и при значительной финансовой, организационной и иной поддержке со стороны государства. Это всё в среднесрочной и долгосрочной перспективе может принести организации ряд значимых преимуществ. Приверженность организации закону и высоким этическим стандартам в деловых отношениях способствуют укреплению ее репутации среди других компаний и клиентов. При этом репутация организации может до некоторой степени служить защитой от коррупционных посягательств со стороны недобросовестных представителей других компаний, государственных органов и органов местного самоуправления. Кроме того, реализация мер по предупреждению коррупции существенно снижает риски применения в отношении организации мер ответственности за подкуп должностных лиц.

\section{ЛИТЕРАТУРА}

1. Генпрокуратура назвала ущерб от коррупционных преступлений за 2018 год [Электронный ресурс] // PИA Новости [ве6-сайт]. URL: https://ria. ru/20190409/1552499622.html. (дата обращения 06.02.2021).

2. Федеральный закон от 25.12.2008 г. № 273-Ф3 «0 противодействии коррупции» [Электронный ресурс] // СПС «КонсультантПлюс». URL: http://www. consultant.ru/document/cons_doc_LAW_82959/ (дата обращения 06.02.2021).

3. Федеральный закон от 05.04.2013 г. № 44-Ф3 «0 контрактной системе в сфере закупок товаров, работ, услуг для обеспечения государственных и муниципальных нужд» [Электронный ресурс] // СПС «КонсультантПлюс». URL: http://www.consultant.ru/document/cons_doc_LAW_144624/ (дата 0бращения 06.02.2021).

4. Попова С.Л. Влияние информационных технологий на формирование устойчивого развития предприятия // Вестник Саратовского социально-экономического университета. 2014. № 1. С. 73-77.

5. Бижоев Б.М. Основы интеллектуальной контрактной системы в сфере государственных закупок // Journal of economic regulation (Вопросы регулирования экономики). 2018. Т. 9. № 1. С. 110-122.

6. Устинова А. Искусственный интеллект подумает над закупками «Газпрома» [Электронный ресурс] // ComNews [веб-caйт]. URL: http://www.comnews.ru/ content/110511/2017-11-16/ii-podumaet-nad-zakupkami-gazproma (дата обращения 06.02.2021).

7. Кузнецов А.А., Кузнецов П.А. Реализация современных информационных технологий в борьбе с коррупцией в Российской Федерации // Юридический факт. 2019. № 61. С. 37-40.

8. IT-система Счетной палаты для удалённого госаудита выявляет уже более 70 видов нарушений [Электронный ресурс] // D-RUSSIA [веб-сайт]. URL: http://d-russia.ru/it-sistema-schetnoj-palaty-dlya-udalyonnogo-gosaudita-vyyavlyaet-uzhe-bolee-70-vidov-narushenij.html (дата 0бращения 06.02.2021).

9. Илий С.К. Предупреждение коррупции в организациях и учреждениях органами прокуратуры // Вестник Всероссийского института повышения квалификации МВД РФ. 2018. № 2 (46). С. 90-95.

(с) Хаснутдинов Ренат Рафаильевич (Khasnutdinoff@mail.ru). 